\title{
Partial shadowing detection based on equivalent thermal voltage monitoring for PV module diagnostics
}

\author{
Dezso Sera, Remus Teodorescu \\ Aalborg University, \\ Institute of Energy Technology \\ 9220 Aalborg, Denmark \\ Email: des@iet.aau.dk, ret@iet.aau.dk
}

\author{
Pedro Rodriguez \\ University of Catalonia, \\ Electrical Engineering Department \\ Colom 1, 08222, Terrassa-Barcelona, Spain, \\ Email: prodriguez@ee.upc.edu
}

\begin{abstract}
Partial shadowing of photovoltaic systems can overproportionally reduce the energy yield and lead to early ageing and failure of the shadowed cells. Large area shadows are relatively easy to detect due to the eminent power reduction and decrease of fill factor. However, small area partial shadows in a larger system do not have a very obvious effect on the output power or fill factor of the PV array and can remain undetected, leading to failure. In this paper a method for detecting small area partial shadows, based on equivalent thermal voltage, is presented. A simplified expression of the equivalent thermal voltage is proposed, which increases the robustness against measurement errors and model limitations at low irradiation conditions. Experimental results confirm the high sensitivity of the method even to a relatively small area shadow, while showing very good robustness against increase in series resistance.
\end{abstract}

\section{INTRODUCTION}

Diagnostics of photovoltaic systems is gaining importance as an additional tool to increase the energy production of the PV system; they work by warning the user about failures or high failure risks, thereby minimizing the time interval with reduced or no power production. Diagnostics generally involve performance monitoring, while keeping track of some key parameters of the module/array, which would reflect changes in the PV generator's health state [1]-[3]. For diagnostic purposes, the main goal generally is to detect if there has been a change in these parameters.

It is well-known that partial shadowing of photovoltaic arrays can overproportionally reduce the system's output power. It has been identified as a major reason for reducing the energy yield of grid connected photovoltaic systems [4].

The problem of partial shading has been extensively treated in the literature, on one hand as a cause of hot-spot formation and cell damage, and, on the other hand, with the utilization of bypass diodes, as a cause of power loss due to average irradiation reduction and mismatch losses [5]-[12]

As presented in [4], in the German 1000-Roofs-PVProgramme that was started in 1990, partial shadowing of PV arrays turned out to be one of the main reasons for the reduction in energy yield [13], [14].
From a diagnostic point of view, it is of particular interest to detect such events, first of all because a failure of one or more cells generally means reduced or no power production of those cells, and therefore the entire submodule, protected by the same bypass diode. A partial shadow has a very similar effect on the module output, and therefore its continuous detection may indicate a failure, e.g. a discoloration of the covering plastic sheet (see Table I).

Secondly, if a single cell from a block of bypass-diode protected series connected cells is covered, it will become reverse biased, and act as a load, burning most of the energy produced by the rest of the cells. Although the number of cells per bypass diode is generally selected such that the cells will be protected from reverse breakdown, a cell continuously exposed to these conditions will age and eventually fail faster.

From the point of view of the MPPT, partial shadows can create multiple peaks on the $P-V$ curve, thus making it difficult to identify the optimum operating point.

\section{Determination of THE EQuiVAlent THERMAL VOLTAGE}

For diagnostic purposes, the simple four-parameter model can be used, with the aim of finding analytical solutions for the parameters, suitable for online calculations. The purpose of this model is to post process the measured $I-V$ curve, calculate certain parameters (as described in the following), and to make an estimation of the module or array state of health from the deviation of these parameter from some predetermined values, e.g. those based on datasheet data or reference measurements. The model is not intended to be able to reproduce the measured $I-V$ curve, (which could have a complicated shape depending on partial shadowing, discoloration of the protective plastic sheet, etc.), and therefore it can be kept simple. It should be emphasized that, as the model is a simplified one, the accuracy of the determined parameters is not as high as in case of a more detailed model.

The general expression of the photovoltaic panel's current as a function of voltage, using the four-parameter model can be expressed as in Eq.(1): 


$$
I=I_{p h}-I_{0}\left(e^{\frac{V+I R_{s}}{V_{t}}}-1\right)
$$

For calculating the panel's parameters, some simplifications to (1) have been made. As the dark saturation current in silicon devices (compared to the exponential term) is very small, the term ' -1 ' can be neglected [17]. Another simplification, which has been made in order to obtain relatively simple and treatable equations approximates the photo-generated current $I_{p h}$ with $I_{s c}\left(I_{p h} \approx I_{s c}\right)$. It is common practice to ignore the difference between the photo-generated current and the shortcircuit current, as it is generally very small [12], [18]-[21].

In this case (1) becomes:

$$
I=I_{s c}-I_{0}\left(e^{\frac{V+I R_{s}}{V_{t}}}\right)
$$

The calculation of the parameters in the following are based on (2). Using the simplification above, the four-parameter model can be reduced to a three-parameter one, with the number of equations and unknowns reduced to three, making the entire calculation relatively straightforward.

The following equations give the expression of the panel current on two of the three main points of the I-V characteristic: (the equation at short-circuit has been canceled due to $\left.I_{p h} \approx I_{s c}\right)$.

At open-circuit conditions:

$$
0=I_{s c}-I_{0} e^{\frac{V_{o c}}{V_{t}}}
$$

and the current at MPP $\left(I_{m p}\right)$ has the following form:

$$
I_{m p}=I_{s c}-I_{0} e^{\frac{V_{m p}+I_{m p} R_{s}}{V_{t}}}
$$

In the third equation, the well-known relation of the derivative of the power with voltage at $M P P$ is used:

TABLE I

MAIN FAULT TYPES AND THEIR POSSIBLE EFFECT ON THE $I-V$ CHARACTERISTICS

\begin{tabular}{l|l}
\hline Type of failure & $\begin{array}{l}\text { Possible effect } \\
\text { on the } I-V \text { curve }\end{array}$ \\
\hline \hline Corrosion [15], [16] & Increased $R_{s}$ \\
\hline Cell interconnect break [15] & $\begin{array}{l}\text { Increased } R_{s}, \\
\text { Decreased } F F, P S\end{array}$ \\
\hline $\begin{array}{l}\text { Decreased transparency } \\
\text { of covering layers }\end{array}$ & \\
\hline - Soiling & Decreased $F F, P S$ \\
\hline - Dust /Stain & Reduced peak power \\
\hline - Discoloration of \\
plastic encapsulates & $\begin{array}{l}\text { Reduced peak power, } \\
\text { Decreased } F F, P S\end{array}$ \\
\hline - Mismatches & Decreased $F F, P S$ \\
\hline $\begin{array}{l}\text { Ageing of the } \\
\text { semiconductor material }\end{array}$ & $\begin{array}{l}\text { Reduced peak power, } \\
\text { Decreased } F F\end{array}$ \\
\hline $\begin{array}{l}R_{s} \text { - module/array series resistance, } \\
F F \text { - Fill Factor, } P S \text { - Partial Shadow }\end{array}$
\end{tabular}

$$
\left.\frac{d P}{d V}\right|_{\substack{I=I_{m p} \\ V=V_{m p}}}=0
$$

The above equation can be expanded as follows:

$\left.\frac{d P}{d V}\right|_{\substack{I=I_{m p} \\ V=V_{m p}}}=\left.\frac{d(V I)}{d V}\right|_{\substack{I=I_{m p} \\ V=V_{m p}}}=V \frac{d I}{d V}+\left.I\right|_{\substack{I=I_{m p} \\ V=V_{m p}}}=0$

which leads to the following:

$$
\left.\frac{d I}{d V}\right|_{\substack{I=I_{m p} \\ V=V_{m p}}}=-\frac{I_{m p}}{V_{m p}}
$$

Considering the fact that $I(V)$ is a transcendent equation, and $I=f(I, V)$, the derivative of current with voltage can be expressed as:

$$
d I=d I \frac{\partial f(I, V)}{\partial I}+d V \frac{\partial f(I, V)}{\partial V}
$$

and therefore:

$$
\frac{d I}{d V}=\frac{\frac{\partial}{\partial V} f(I, V)}{1-\frac{\partial}{\partial I} f(I, V)}
$$

Therefore, collecting Equations (3), (4) and executing the derivatives in (9), the three equations, forming the equation system for finding the panel model parameters, become:

$$
\left\{\begin{array}{l}
0=I_{s c}-I_{0} e^{\frac{V_{o c}}{V_{t}}} \\
I_{m p}=I_{s c}-I_{0} e^{\frac{V_{m p}+I_{m p} R_{s}}{V_{t}}} \\
\frac{I_{m p}}{V_{m p}}=\frac{I_{0} e^{\frac{V_{m p}+I_{m p} R_{s}}{V_{t}}}}{V_{t}\left(1+\frac{I_{0} R_{s} e^{\frac{V_{m p}+I_{m p} R_{s}}{V_{t}}}}{V_{t}}\right)}
\end{array}\right.
$$

Solving the above system of equations will result in the solution for $I_{0}, R_{s}$, and $V_{t}$ as follows:

$$
\begin{gathered}
I_{0}\left(V_{t}\right)=\frac{I_{s c}}{e^{\frac{V_{o c}}{V_{t}}}} \\
R_{s}\left(V_{t}\right)=\frac{V_{o c}-V_{m p}+V_{t} \ln \left(\frac{I_{s c}-I_{m p}}{I_{s c}}\right)}{I_{m p}} \\
V_{t}=\frac{\left(2 V_{m p}-V_{o c}\right)\left(I_{s c}-I_{m p}\right)}{I_{m p}-\left(I_{s c}-I_{m p}\right) \ln \left(\frac{I_{s c}-I_{m p}}{I_{s c}}\right)}
\end{gathered}
$$

which contains only parameters given in the product datasheet or that are directly measurable.

In order to obtain a simpler result for $V_{t}$, an additional simplification can be done when differentiating the power with voltage at MPP. Instead of using Eq. (9), which takes into account that $I=f(I, V)$ (as $I(V)$ is transcendent), a simpler formula is used, which disregards at the derivation that $I=f(I, V)$. In other words, the first term on the right side of (8) is disregarded. Equation (4) can be revisited, multiplied 
with $V_{m p}$ (in order to obtain $P_{m p}$ ), and simply differentiated with $V_{m p}$. This results in:

$$
\left.\frac{d P}{d V}\right|_{M P P}=I_{s c}-\frac{I_{s c} e^{\frac{V_{m p}+I_{m p} R_{s}}{V_{t}}}}{e^{\frac{V_{o c}}{V_{t}}}}\left(\frac{V_{m p}}{V_{t}}+1\right)=0
$$

Inserting the expression of $R_{s}$ from (12) into the above equation results in:

$$
I_{s c}-\left(I_{s c}-I_{m p}\right)\left(\frac{V_{m p}}{V_{t}}+1\right)=0
$$

Solving the above for $V_{t}$, results in the very simple expression:

$$
V_{t}=\frac{\left(I_{s c}-I_{m p}\right) V_{m p}}{I_{m p}}
$$

The above formula gives a reasonable approximation precision, while avoiding the calculations of logarithmic functions, offering a simpler formulation for $V_{t}$, and at the same time decreasing the sensitivity to measurement errors of $I_{s c}$ and $I_{m p}$ when the difference between them is small, i.e. at low irradiation conditions.

In order to verify the validity of this simplification, simulations results using expressions (11), (12), and (13) as well as the simplified parameters based on (16), have been compared to experimental data (Fig. 1 and 2). In Fig. 2 can be seen the fitting errors produced by the models using normal and simplified formulation of parameters when compared to experimental measurements.

As is shown in Fig. 3, in most conditions the parameters found by the simplified expression provide fitting quality similar to those calculated starting with Eq. (13), with even smaller fitting errors in some cases.

Although the fitting error increases as the irradiation decreases, it remains relatively low for both parameter sets (Fig. 3).

The parameters determined in this section were not calculated with the purpose of finding the corresponding physical parameters of the photovoltaic module or cell, e.g. series resistance, dark saturation current or thermal voltage. In this context these values are treated as parameters of an exponential function, which has to fulfill the conditions given by (3), (4), and (5).

Conclusions regarding the state of health of the module can be made by comparing them to reference values, determined based on a controlled measurement, where the conditions of the measurement e.g. irradiation, temperature, partial shadowing are known, or datasheet values.

\section{PARTial Shadowing DeTECTION BASED ON THERMAL VOLTAGE MONITORING}

Shadowing part of a PV panel creates a deviation of its $I-V$ curve from the normal characteristic. Depending on the area, intensity, and position of the shadow in respect to the bypass diodes, it creates different shapes of the $I-V$ curve (Fig. 4).
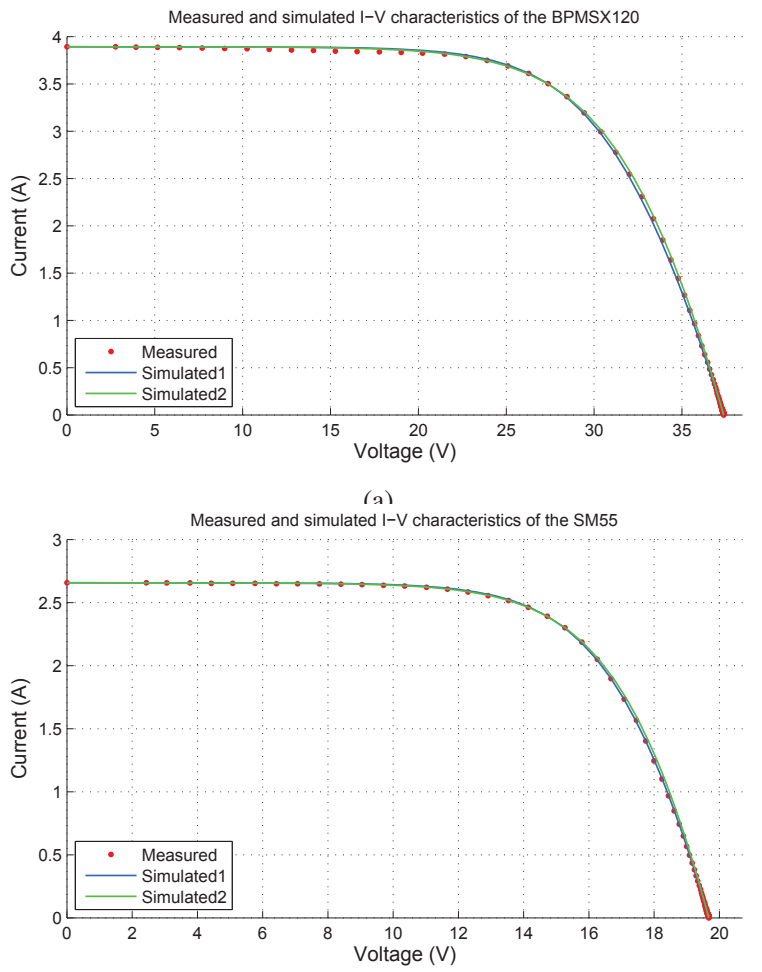

(h)

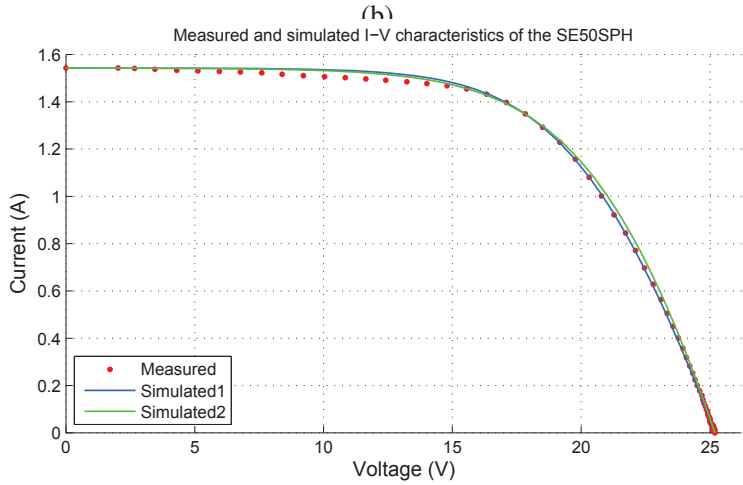

(c)

Fig. 1. Measured and simulated $I-V$ curves of three crystalline silicone panels, the BPMSX120 [22] (a), the SM55 [23] (b), and the SE50SPH [24], (c). 'Simulated1' has been created with single diode simple model using the parameters as calculated in Eq (11), (13) and (12), while 'Simulated2' has been created using the same model with the simplified expression of $V_{t}$ (and consequently $R_{s}$ ), according to (16).

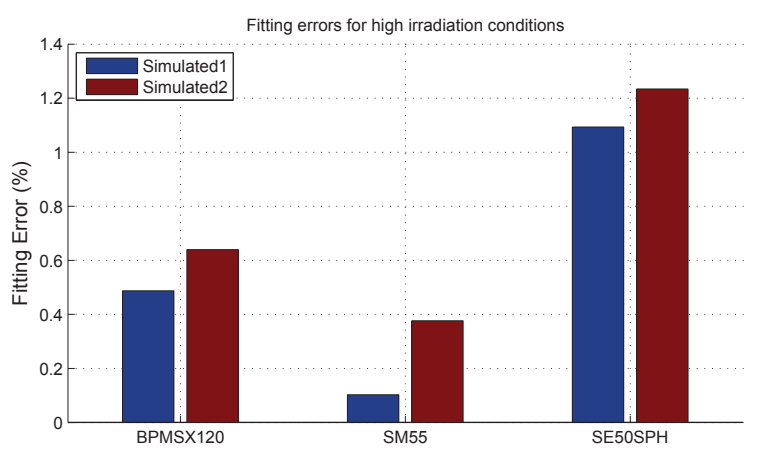

Fig. 2. Area fitting errors for three modules, when using the normal and simplified formulation of the parameters (measurements taken in high irradiation conditions). 


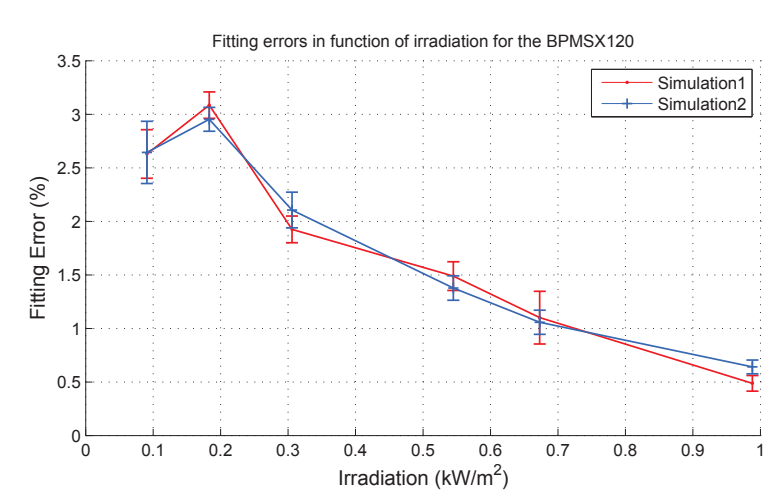

Fig. 3. Area fitting errors versus irradiation for the normal ('Simulated 1') and simplified ('Simulated 2') parameter sets. The data points represent the mean of the results based on 15 consecutive measurements, repeated every 12 seconds under the same conditions, and the vertical bars denote the standard deviations of the results over the respective set of measurements.

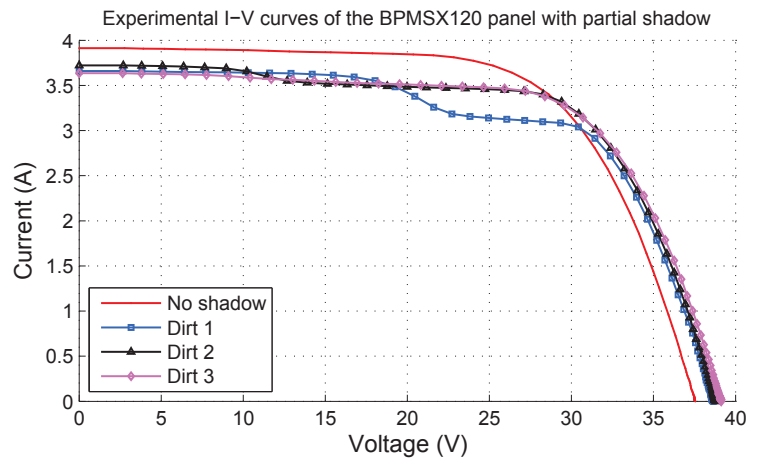

(a)

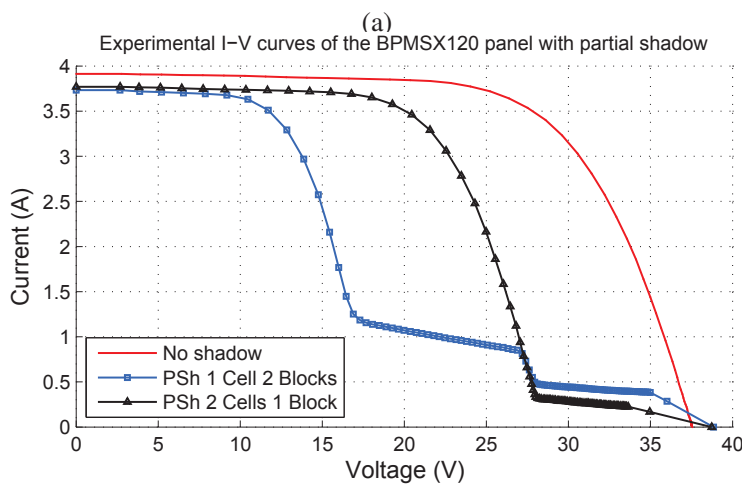

(b)

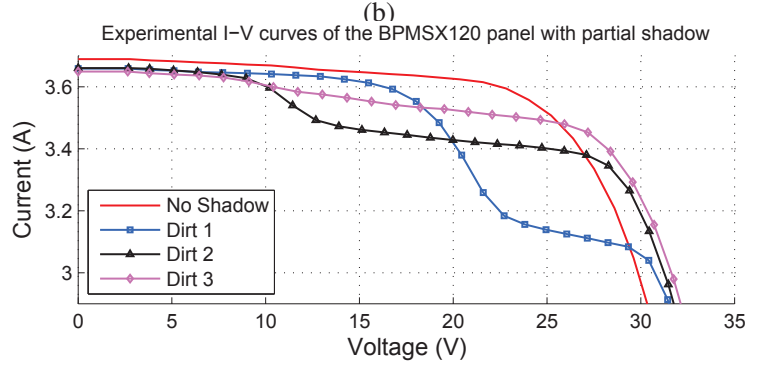

(c)

Fig. 4. Measured I-V curves of a BPMSX120 module under different shadowing conditions, normalized to the same irradiation. For the sake of clarity, 4(a) has been repeated on 4(c) showing the curves in the vicinity of short-circuit current.

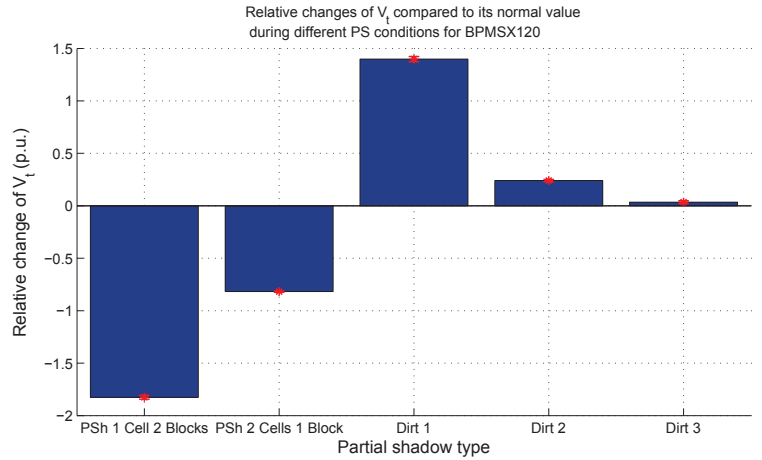

Fig. 5. Bar plot of the calculated thermal voltages for the BPMSX120 in different partial shadowing conditions. The data values represent the mean of the results based on 15 consecutive measurements repeated every 12 seconds under the same conditions, and the vertical bars denote their standard deviations over the respective set of measurements.

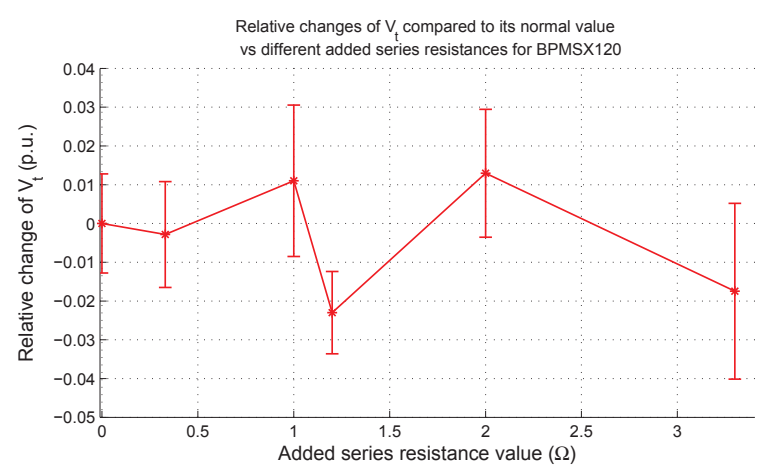

Fig. 6. Calculated thermal voltages versus various series resistance values added to the panel. The data points represent the mean of the results based on 15 consecutive measurements repeated every 12 seconds under the same conditions, and the vertical bars denote the standard deviations of the results over the respective set of measurements.

The simplified form of the thermal voltage expression (Eq. (16)) suggests that changes in the module MPP current $\left(I_{m p}\right)$ relative to its short-circuit current, as well as changes in $V_{m p}$ have direct impact on the value of $V_{t}$. Indeed, the experimental measurements (Fig. 5) indicates that $V_{t}$ shows substantial sensitivity, even to a relatively small partial shadow, e.g. the ones presented on Fig. 4(a).

During high irradiation conditions, the simple fourparameter model exhibits good fitting with experimental measurements and therefore the partial shadowing condition can be detected solely based on the value of the calculated $V_{t}$. Confronting Fig. 5 with Fig. 4, it can be observed that partial shadows corresponding to 4(a) produce an increased $V_{t}$, while partial shadows corresponding to 4(b) will strongly decrease the value of $V_{t}$. This property can be explained by the change of the $M P P$ relative to the ideal coordinates $\left(V_{m p}\right.$ and $\left.I_{m p}\right)$, which is reflected by $V_{t}$, and it provides additional information about the type of the shadow. This method of partial shadow detection shows robustness against changes in series resistance (see Fig. 6).

However, during low irradiation conditions, the sensitivity of the method decreases due to the restrictions of the model 


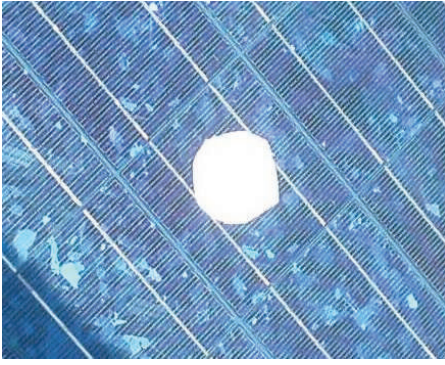

(a)

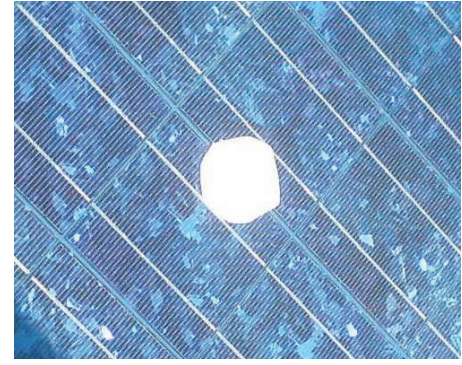

(b)

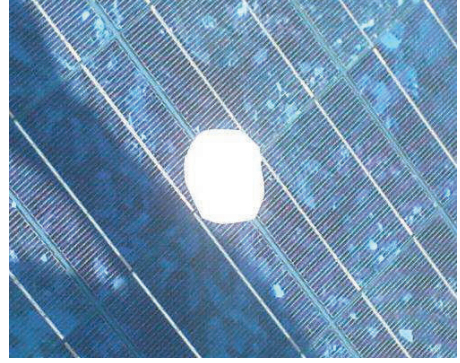

(c)

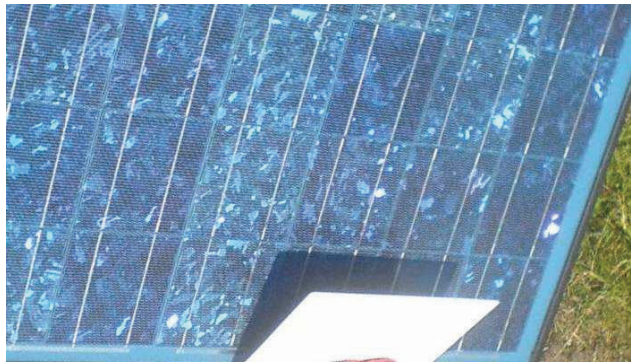

(d)

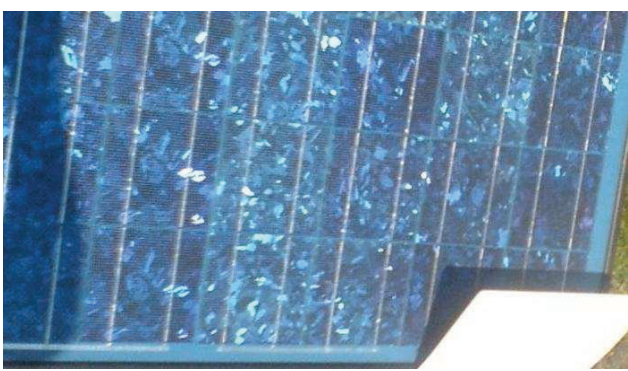

(e)

Fig. 7. Partial shadows on the BPMSX120 panel for experimental measurements used to create the characteristics on Fig. 4. The photo on (a) shows 'Dirt 1', which is a round white spot of $\approx 10 \mathrm{~cm}^{2}$ in the middle of a cell, on (b) the same spot is between two adjacent cells, covering parts from both of them ('Dirt 2'), while on (c) the spot is at the meeting points of four cells, corresponding to 'Dirt 3'. The photo on Fig. 7(d) shows the shadowing of two cells, which belong to two different bypass diode protected submodule,('PS 1 Cell 2 Blocks') while (e) shows the shadowing of two cells within the same submodule ('PS 2 Cells 1 Block').

used to calculate $V_{t}$. As it is shown on Fig. 8, the thermal voltage exhibits a dependency on the irradiation, showing an increasing value as the irradiance falls. Therefore, at irradiations below 40-50\% of STC, the increased value of $V_{t}$ can trigger a false positive for partial shadows like 'Dirt 2' and 'Dirt 3' on Fig. 4(a). Nevertheless, partial shadowing, such as the ones presented in Fig. 4(b) produce a strong decrease of $V_{t}$, together with a decrease of fill factor, thereby their presence can be detected also at low irradiation conditions using the above method.

\section{CONCLUSIONS}

A diagnostic function, aimed at detecting partial shadowing based on thermal voltage monitoring is proposed in this paper. The method enables the detection of partial shadows with good sensitivity, while keeping strong robustness against changes in the panel's series resistance. A simplified expression for the equivalent thermal voltage has been proposed, which avoids the logarithmic calculations and therefore decreases the errors introduced at low irradiation conditions. The weak point of the method is that its sensitivity decreases in low irradiation conditions.
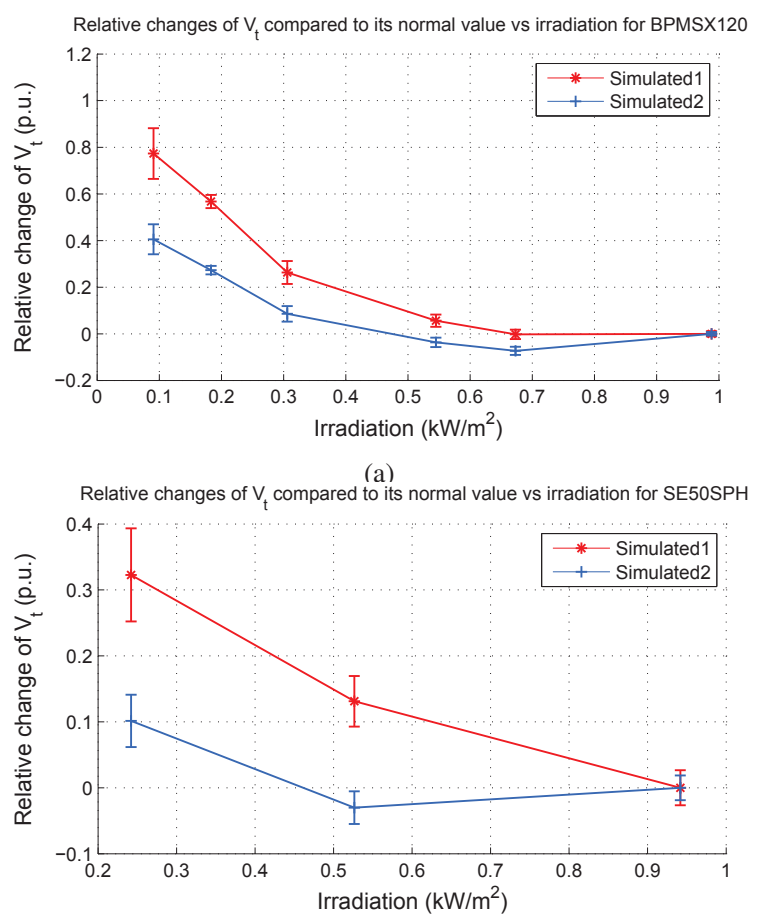

(b)

Fig. 8. Deviation of the thermal voltage from its normal value versus irradiance, normalized to the value calculated from the measurement at the highest irradiation. 'Simulated 1' represents $V_{t}$ calculated based on (13), while 'Simulated 2' denotes the thermal voltage according to (16) The data points are the results of 15 consecutive measurement in the same conditions, and the vertical bars denote the standard deviations of the results over the set of measurements. 


\section{REFERENCES}

[1] D. King, W. Boyson, and J. Kratochvil, "Analysis of factors influencing the annual energy production of photovoltaic systems," in Photovoltaic Specialists Conference, 2002. Conference Record of the Twenty-Ninth IEEE, 2002, pp. 1356-1361.

[2] F. De Lia, S. Castello, and L. Abenante, "Efficiency degradation of csilicon photovoltaic modules after 22-year continuous field exposure,' in Photovoltaic Energy Conversion, 2003. Proceedings of 3rd World Conference on, vol. 2, 2003, pp. 2105-2108 Vol.2.

[3] M. Fuentes, G. Nofuentes, J. Aguilera, D. Talavera, and M. Castro, "Application and validation of algebraic methods to predict the behaviour of crystalline silicon pv modules in mediterranean climates," Solar Energy, vol. 81, no. 11, pp. 1396-1408, Nov. 2007. [Online]. Available: http://www.sciencedirect.com/science/article/ B6V50-4N3PY20-3/2/65e6c09fcced5739b8714a81907a5e6c

[4] A. Woyte, J. Nijsa, and R. Belmansa, "Partial shadowing of photovoltaic arrays with different system configurations-literature review and field test results," Solar energy, vol. 74, pp. 217-, 2003.

[5] H. Rauschenbach, "Electrical output of shadowed solar arrays," Electron Devices, IEEE Transactions on, vol. 18, no. 8, pp. 483-490, 1971

[6] J. Bishop, "Computer simulation of the effect of electrical mismatches in photovoltaic cell interconnection circuits." Solar cells, vol. 25, pp. 73-89, 1988.

[7] V. Quaschning and R. Hanitsch, "Numerical simulation of photovoltaic generators with shaded cells," in Universities Power Engineering Conference, vol. 30th, 1995, pp. 583-586.

[8] A. Kovach and J. Schmid, "Determination of energy output losses due to shading of building-integrated photovoltaic arrays using a raytracing technique," Solar Energy, vol. 57, no. 2, pp. 117-124, Aug. 1996. [Online]. Available: http://www.sciencedirect.com/science/article/ B6V50-3WFND58-4/2/af38140e02135366cdf5bb007ad29570

[9] H. Nagayoshi and M. Atesh, "Partial shading effect emulation using multi small scale module simulator units," in Photovoltaic Specialists Conference, 2005. Conference Record of the Thirty-first IEEE, 2005, pp. $1710-1713$.

[10] R. Pinkerton, "Solar array string characteristics in strange places," in Energy Conversion Engineering Conference and Exhibit, 2000. (IECEC) 35th Intersociety, vol. 1, 2000, pp. 681-691 vol.1.

[11] D. King, J. Dudley, and W. Boyson, "PVSIM: a simulation program for photovoltaic cells, modules, and arrays," in Photovoltaic Specialists Conference, 1996., Conference Record of the Twenty Fifth IEEE, 1996, pp. 1295-1297.
[12] N. Kaushika and N. Gautam, "Energy yield simulations of interconnected solar PV arrays," Energy Conversion, IEEE Transactions on, vol. 18 , no. 1 , pp. $127-134,2003$

[13] B. Decker and U. Jahn, "Performance of 170 grid connected PV plants in Northern Germany-Analysis of yields and optimization potentials," Solar Energy, vol. 59, no. 4-6, pp. 127-133, 1997. [Online]. Available: http://www.sciencedirect.com/science/article/ B6V50-3SP7889-8/2/95e00e68fdfc23fe57766e062647f5e3

[14] T. Erge, V. Hoffmann, K. Kiefer, E. Rossler, U. Rindelhardt, G. Teichmann, B. Decker, J. Grochowski, G. Heilscher, M. Schneider, G. Blasser, H. Ossenbrink, H. Becker, W. Vaassen, B. Genennig, H. Riess, and P. Sprau, "The german 1000-roofs-pv-programme - a resume of the 5 years pioneer project for small grid-connected pv systems." in Proceedings of the 2nd World Conference on PVSEC, Vienna, 1998, p. 2648 Ü2651.

[15] V. Benda, "Solar cell physics and construction," November 2008.

[16] H. Lukamp, "Reliability study of grid connected PV systems," IEA-PVPS, Report IEA-PVPS Task7 IEA T7-08: 2002, March 2002. [Online]. Available: http://www.iea-pvps.org/products/download/rep7_ 08.pdf

[17] M. Chegaar, Z. Ouennoughi, and A. Hoffmann, "A new method for evaluating illuminated solar cell parameters," Solid-state electronics, vol. 45, pp. 293-, 2001, oK

[18] G. Walker, "Evaluating MPPT converter topologies using a Matlab PV model," Journal of Electrical and Electronics Engineering, Australia, vol. 21, pp. 49-55, 2001.

[19] W. Xiao, W. Dunford, and A. Capel, "A novel modeling method for photovoltaic cells," in Power Electronics Specialists Conference, 2004. PESC 04. 2004 IEEE 35th Annual, vol. 3, 2004, pp. 1950-1956 Vol.3.

[20] J. Gow and C. Manning, "Development of a photovoltaic array model for use in power-electronics simulation studies," Electric Power Applications, IEE Proceedings-, vol. 146, no. 2, pp. 193-200, 1999.

[21] G. Kuntz and A. Wagner, "Internal series resistance determinated of only one IV-curve under illumination," in 19th Photovoltaic Solar Energy Conference Paris, 2004.

[22] B. Petrol, BP MSX 120 Data Sheet, BP Solar, 2001.

[23] Siemens, Siemens Solar Module SM 55 Data Sheet, Siemens Solar GmbH, Postfach 4607 05, D-80915 München, Germany, 1998.

[24] Solel, Solel SE50SPH Data Sheet, Solel. 